\title{
Melt-spun polypropylene filaments containing paraffin microcapsules for multifunctional hybrid yarns and smart thermoregulating thermoplastic composites
}

\author{
G. Fredi ${ }^{1 *}, H$. Brünig ${ }^{2}$, R. Vogel $^{2}$, C. Scheffler ${ }^{2}$ \\ ${ }^{1}$ University of Trento, Department of Industrial Engineering, Via Sommarive 9, 38123 Trento, Italy \\ ${ }^{2}$ Leibniz-Institut für Polymerforschung, Hohe Straße 6, 01069 Dresden, Germany
}

\begin{abstract}
The present work focuses on the development of polypropylene (PP) filaments containing paraffin microcapsules (MC), aimed at being incorporated in hybrid yarns to produce multifunctional thermoplastic laminates for thermal energy storage (TES). Benchmark experiments carried out on a small-scale melt compounder and piston-type melt spinning device resulted in the successful production of single filaments containing up to $30 \mathrm{wt} \%$ of MC, with diameters of $70-140 \mu \mathrm{m}$ depending on the collection speed and a surface roughness that increases with the MC content. An increase in the MC fraction also determines a rise in the complex viscosity, but this effect is less evident at higher shear rates and likely almost negligible at the deformation rates typical of the spinning process. Although the MC have a considerable thermal stability, the compounded mixtures reported a sensible mass loss in isothermal thermogravimetric analysis (TGA) tests, which is linked to a not negligible MC damage during the compounding. Nevertheless, differential scanning calorimetry (DSC) on the spun filaments evidenced an increase in the phase change enthalpy with the MC content up to approx. $48 \mathrm{~J} / \mathrm{g}$, which is remarkably higher than that of similar systems reported in the literature. The elastic modulus and the properties at break decrease with an increase in the MC content, but the fiber strength is acceptable to produce a hybrid yarn and a thermoplastic laminate up to a $\mathrm{MC}$ fraction of $20 \mathrm{wt} \%$.
\end{abstract}

Keywords: polymer composites, multifunctional composites, phase change microcapsules, melt spinning, thermal energy storage

\section{Introduction}

The increasing demand for materials with high specific stiffness and strength and for structures with lightweight complex geometries has considerably expanded the use of polymer-matrix composites as structural materials, especially in weight-critical applications in the automotive, aerospace, sports, and energy industries $[1,2]$. In a polymer composite, the matrix can be constituted by a thermoplastic or a thermosetting polymer, but for high-performance composites the currently preferred choice is to couple continuous reinforcing fibers with a thermosetting resin, due to the generally higher mechanical properties, the better thermal stability and the wellestablished processing techniques $[2,3]$.

However, some important drawbacks of thermosets, such as the low recyclability and the generally limited strain to failure, have paved the way for the growth of the market of thermoplastic laminates in the last decades. They have emerged as strong competitors of their thermosetting counterparts due to their remarkable advantages, as they can be more easily recycled, post-thermoformed, repaired and welded, exhibit an infinite shelf life, require a shorter processing cycle, and feature higher toughness and impact properties [3]. On the other hand, they must 
be processed in the molten state, and the high viscosity of the polymer melt may cause a de-alignment of reinforcing fibers and an inadequate penetration in the fiber tow, which could in turn lead to the production of laminates showing unacceptably low quality and properties [4].

These problems could be alleviated by using reactive in-situ polymerizing thermoplastic matrices, which exhibit low viscosity and can be processed with techniques typical of thermosetting resins $[5,6]$. However, these formulations are nowadays available only for few acrylic polymers and a limited range of applications. For traditional thermoplastics that must be processed in the molten state, the problems related to the high melt viscosity can be solved by reducing the melt flow distance during the laminate consolidation [4]. Several methods are nowadays available to achieve a fine matrix dispersion among the reinforcing fiber tows before the preforming steps, such as the film stacking, melt impregnation, powder impregnation, co-woven, and hybrid yarn techniques [7]. Among these methods, the production of commingled hybrid yarns combining reinforcement and matrix filaments allows the manufacture of soft, flexible and drapable components [8], which makes it the technique of election in the textile composite industry and to produce complex-shaped parts [7,9].

The use of hybrid yarns also allows the homogeneous dispersion of other functional fillers, such as sensors, dyes, or conductive particles, which can be integrated in the matrix filaments or inserted as an additional filament type [10-13]. This is especially interesting for the development of multifunctional composites, in which the combination of different fillers results in a unique set of properties, tailored to simultaneously sustain stimuli of different nature and perform various tasks at the same time [14, 15].

An interesting feature that can be added to a structural composite is the thermal energy storage (TES) ability, defined as the capacity of temporarily storing heat that can be released where and when needed, thereby filling the thermal energy demand-supply gap [16]. TES technologies are nowadays applied to accumulate excess heat in the solar-thermal power plants, to help regulating the indoor temperature in buildings, or as a temperature management tool for electronic components [17-19]. Structural composites exhibiting also TES capability could be useful where weight/volume savings and thermal management are equally important, such as in the automotive, portable electronics and sports/technical garments industries. However, limited research has been carried out so far to produce such structural TES composites. Some examples are reported in the literature of continuous or discontinuous fiber composites with thermosetting [20-24], thermoplastic [25-28], or reactive thermoplastic $[29,30]$ matrices. However, the research on continuous-fiber composites with a traditional thermoplastic matrix and TES capability is limited to a single work [25], in which the compaction is performed via film stacking.

The most widely used TES technique in the temperature range $0-100^{\circ} \mathrm{C}$ is to exploit the latent thermal energy stored and released by organic phase change materials (PCMs) such as paraffin waxes, which undergo a solid-liquid phase transition in a narrow temperature range $[16,31,32]$. Paraffins exhibit a high energy density and their phase change temperature can be easily tuned by choosing the appropriate molecular weight; they are inexpensive, largely available, not toxic and easy to handle $[31,33]$. On the other hand, they need to be confined to avoid leakage above the melting temperature, which is commonly achieved via encapsulation in micro/nano-shells [34-36], as this is not only a reliable method for confinement, but it is also one of the most convenient PCM forms to handle and disperse in polymers, concrete, and other matrices [37-39].

The production of polymer fibers containing a PCM has recently grown to fabricate smart thermoregulating textiles for a broad range of applications, including clothing, footwear, blankets, carpets and mattresses, but also advanced applications like sports apparel, spacesuits, and automotive and aerospace textiles [40-42]. The incorporation of PCMs into polymer fibers can be achieved with different techniques, such as the direct melt/solvent spinning of polymers containing free PCM [43], the spinning of bi-component fibers with the PCM as the core and the matrix material as the sheath $[40,44]$, the coating of spun fibers with a paste or adhesive containing the PCM [45], and the addition of PCM microcapsules to the melt/solvent spun polymer [46]. Although all these techniques are suitable for textile applications, only a microencapsulated PCM can be used to produce PCM-enhanced polymer fibers for a hybrid yarn, as the remelting of the matrix during consolidation might cause PCM leakage, if this is not encapsulated. 
Even though there are several examples in the literature of polymer fibers containing PCM microcapsules [43-48], the process has been studied only to meet the requirements of the textile industry, and not to produce hybrid yarns for thermoplastic laminates. This investigation would be interesting in order to produce multifunctional hybrid yarns containing not only a PCM, but also other microencapsulated functional fillers such as self-healing, antimicrobial, and fire-retardant agents $[49,50]$.

The aim of the present work is to develop and characterize polymer fibers containing paraffin microcapsules for a subsequent realization of a PCM-enhanced thermoplastic laminate, which, to the best of the authors' knowledge, has never been investigated in the open scientific literature. The chosen matrix was a polypropylene (PP), as this polymer is widely used in fiber-reinforced thermoplastic composites [3], and widely applied to produce hybrid yarns [4, $8,12,51]$. The chosen PP was a spinnable grade with low melt viscosity, to limit the capsule damage during spinning. Filaments were produced via melt spinning, as this is the most widely used and environmentally friendly technique due to the absence of solvents, the high productivity, and the simplicity of the process [52]. In the present work, this technique has been chosen also because it is the typical method to produce polyolefin fibers. Filaments with different amounts of microcapsules (10, 20 and $30 \mathrm{wt} \%$ ) have been produced and characterized, and the characterization aimed at assessing not only the mechanical and thermal properties of the produced filaments, but also the impact of the spinning process on the integrity of the microcapsules, as the high temperature and melt viscosity could cause capsule breakage and PCM degradation. The production of a laminate and a trial to produce hybrid yarns will be object of upcoming work.

\section{Experimental}

\subsection{Materials}

The employed matrix was a polypropylene (PP) supplied by Toray (Tokyo, Japan) in the form of pellets and characterized by a noticeable melt fluidity. PP is a common choice for the spinning of filaments [52] and as a matrix for composites [3], and this particular low-viscosity grade was chosen to minimize the shear stresses on the microcapsules during processing and to manage the unavoidable rise in viscosity caused by the addition of a solid particulate filler [53]. The
PCM phase was the MPCM43D, supplied by Microtek Laboratories inc. (Dayton, OH, US). It consists in core-shell microcapsules (MC) with a paraffinic core and a melamine-formaldehyde-based shell, having an average diameter of $20 \mu \mathrm{m}$, a declared phase change enthalpy of $200 \mathrm{~J} / \mathrm{g}$ and a declared thermal stability up to $250^{\circ} \mathrm{C}$.

\subsection{Sample preparation: melt compounding and melt spinning}

PP-MC monofilaments were prepared through melt compounding and melt spinning. The melt compounding step was necessary to uniformly disperse the microcapsules and to prevent clogging during spinning, as a preliminary attempt to avoid the melt mixing and manually mix the microcapsules and the PP granules resulted in severe inhomogeneity of the spun filament and considerable obstruction of the die capillary. PP granules and microcapsules were meltmixed in a small-scale microcompounder Xplore DSM 15, equipped with conical co-rotating screws. The microcapsules were introduced gradually in the compounding chamber, only after the PP was completely molten. The mixing was performed in batches of $12 \mathrm{~g}$, at $190^{\circ} \mathrm{C}$, for 5 minutes, at a rotor speed of $80 \mathrm{rpm}$. These mild parameters were chosen to preserve the integrity of the thin microcapsule shell, and they were proven sufficient to obtain a homogeneous mix. The compounded material was then pelletized to ease the spinning process. Three compositions were produced, containing 10, 20 and $30 \mathrm{wt} \%$ of microcapsules. The spinning was performed with an IPF in-house designed and built laboratory-scale piston spinning device with a chamber size of $10 \mathrm{~g}$. Monofilaments were spun through a single-hole die with capillary length and diameter of 0.6 and $0.3 \mathrm{~mm}$, respectively. The spinning temperature was $180^{\circ} \mathrm{C}$ up to a microcapsules content of $20 \mathrm{wt} \%$, and $185^{\circ} \mathrm{C}$ for the sample containing $30 \mathrm{wt} \%$ of MC. As-spun filaments were collected at a take-up speed of 50, 100 and $200 \mathrm{~m} / \mathrm{min}$. The prepared compositions will be from now on called PP-MCx, where x represents the $\mathrm{MC}$ weight fraction in the sample.

\subsection{Characterization}

The characterization involved both the compounded PP-MC mixtures and the spun filaments, which will be identified as 'as-compounded' (or with a 'c' subscript) and 'as-spun' (or with a 's' subscript), respectively. 
The morphology of the filaments and the distribution of the microcapsules were investigated through optical and scanning electron microscopy. Optical microscope (OM) images of the lateral surface and the polished cross section of the filaments were acquired at different magnification levels with the optical microscope Keyence VHX-2000 (Osaka, Japan), equipped with a VHX-S15 stage control software and a VH-Z500 objective lens. The diameter of single filaments was measured on the cross sections through the software ImageJ. The OM images of the fiber cross section were obtained by embedding the fibers in cylindrical, easy-to-handle epoxy beads, which were subsequently grinded with a sequence of abrasive papers of decreasing roughness and then polished with the help of polishing clothes. The scanning electron microscope (SEM) Zeiss Ultra Plus (Oberkochen, Germany) was employed to acquire micrographs of the lateral surface of the filaments, after Pt-Pd sputter-coating.

The density of PP and MC was measured with a helium Ultrapycnometer 1000 (Quantachrome Instruments, Boynton Beach, FL, US). Approximately 5 grams of material were loaded in the measurement chamber and, as normally done with He pycnometers, several measurements were acquired until a stable output was obtained. The density was calculated as the average of the last 15 measurements. The density of the compounded and as-spun filaments was calculated with the mixture rule, considering a pore volume fraction equal to zero. As the density of a composite with zero porosity can be calculated by the average density of the constituents weighted by the volume fraction of the constituents, the $\mathrm{MC}$ volume fraction $\left(\vartheta_{M C}\right)$ was first calculated with Equation (1) as:

$$
\vartheta_{\mathrm{MC}}=\frac{\omega_{\mathrm{MC}}}{\omega_{\mathrm{MC}}+\left(1-\omega_{\mathrm{MC}}\right) \frac{\rho_{\mathrm{MC}}}{\rho_{\mathrm{PP}}}}
$$

where $\omega_{\mathrm{MC}}$ is the $\mathrm{MC}$ weight fraction of each composition, and $\rho_{\mathrm{MC}}$ and $\rho_{\mathrm{PP}}$ are the measured density values of MC and PP, respectively. The density of the prepared samples $(\rho)$ was then calculated via the mixture rule with the Equation (2) as:

$\rho=\rho_{\mathrm{MC}} \cdot \vartheta_{\mathrm{MC}}+\rho_{\mathrm{PP}}\left(1-\vartheta_{\mathrm{MC}}\right)$

The density calculated via the Equation (2) was then compared with that measured on some selected samples, namely the three filaments collected at $100 \mathrm{~m} / \mathrm{min}$.
Rheological tests were carried out on as-compounded samples, to assess how the MC fraction influences the viscosity and the other rheological parameters affecting the behavior of polymer melts during spinning. These tests were performed by means of an ARES G2 rotational rheometer (TA Instruments, US) under small amplitude oscillatory frequency sweeps, in a parallel-plate configuration (gap $1.5 \mathrm{~mm}$, diameter $8 \mathrm{~mm}$ ), at $190^{\circ} \mathrm{C}$ under nitrogen atmosphere. Each test started 4 minutes after the insertion of the specimen, to ensure the thermal equilibrium. The storage and loss moduli were measured as a function of the shear frequency, and the tests also allowed the calculation of the $\tan \delta$ and the complex viscosity. The tests were performed on the neat PP and the three compounded PP-MC mixtures. To isolate the effect of the MC addition, the test on the neat PP was not performed on virgin PP granules, but on a sample previously subjected to melt compounding with the same parameters used for the mixtures. To achieve a better understanding of the MC effect on the PP rheology, the test was performed also on samples containing 2, 5 and $15 \mathrm{wt} \%$ of MC, prepared via melt compounding in the same way as the other compositions.

Differential scanning calorimetry (DSC) was carried out with a TA Instruments Q2000 calorimeter (New Castle, DE, US) on specimens of approx. $3 \mathrm{mg}$. Each sample was subjected to a heating-cooling-heating test sequence from -20 to $180^{\circ} \mathrm{C}$, at $10^{\circ} \mathrm{C} / \mathrm{min}$, under nitrogen atmosphere. The tests, performed on all the as-compounded and the as-spun samples, allowed the measurement of the melting/crystallization temperatures and enthalpy values of the PCM $\left(T_{\mathrm{m}}, T_{\mathrm{c}}\right.$, $\left.\Delta H_{\mathrm{m}}, \Delta H_{\mathrm{c}}\right)$, related to the effective microcapsule content and integrity. The same tests were performed also on the neat microcapsules and PP granules.

Thermogravimetric analysis (TGA) was carried out with TA Instruments Q500 thermobalance, on samples of approx. 3-4 $\mathrm{mg}$, at a heating rate of $10^{\circ} \mathrm{C} / \mathrm{min}$ up to $700^{\circ} \mathrm{C}$, under nitrogen atmospheres. The tests allowed the calculation of the temperatures corresponding to a mass loss of 1,3 and $5 \mathrm{wt} \%\left(T_{1 \%}, T_{3 \%} T_{5 \%}\right)$, as well as the temperature of maximum degradation rate $\left(T_{\mathrm{d}}\right)$, taken as the peak of the mass loss derivative. As the residence time of the material in the spinning chamber is of several minutes, isothermal tests were also performed on the neat microcapsules and the as-compounded samples, to investigate the thermal stability of the MC phase at the selected spinning 
temperature. The specimens were subjected to a heating ramp of $50^{\circ} \mathrm{C} / \mathrm{min}$ up to 180,190 and $200^{\circ} \mathrm{C}$, followed by an isothermal scan for 20 minutes.

The mechanical properties of the as-spun filaments were investigated through single-filament tensile tests, performed with a Textechno Favigraph singlefiber analyzer (Mönchengladbach, Germany). Single filaments were clamped with an initial length of $10 \mathrm{~mm}$ and tested at $15 \mathrm{~mm} / \mathrm{min}$, with a preload of $1 \mathrm{~N}$. At least 20 specimens were tested per composition. Important mechanical parameters were extracted from the test, such as the strain at break $\left(\varepsilon_{\mathrm{b}}\right)$ and the filament tenacity $\left(\sigma_{\mathrm{M}}\right)$, defined as the maximum load divided by the fiber fineness and measured in $\mathrm{cN} /$ tex. The elastic modulus $(E)$ was measured as the slope of the secant to the stress-strain curve between the strain values 0.05 and $0.25 \%$.

\section{Results and discussion}

\subsection{Microstructural properties}

Figure 1 reports the optical microscope images of the produced filaments. The surface of the neat PP fibers (Figure 1a) is smooth and regular, and this is observed independently from the collection speed. On the other hand, the surface of the PCM-containing fibers is irregular, as some capsules are visible as projections underneath the fiber surface, and this effect increases with increasing MC content. This peculiar fiber morphology, which may be an issue for the production of fibers for the textile industry, depends largely on the capsule dimensions, as they are of the same order of magnitude as the fiber diameter. Some strategies to avoid this effect could involve the adoption of smaller capsules [47] or their confinement in the fiber core by producing core-sheath filaments [54]. However, this is not a concern for the production of hybrid yarns, as the PP-MC filaments are only a way to distribute the matrix and the particles more homogeneously in the final laminate, and an increased fiber roughness may also improve the mechanical interlocking between the different fiber types in the hybrid yarn and ease the yarn handling [55]. Moreover, as clearly observable from the SEM micrographs (Figure 2), the capsules are completely covered with PP matrix, which prevents capsule damage and removal in the operations after spinning. The fibers collected at 50 and $100 \mathrm{~m} / \mathrm{min}$ present the typical pattern of polymer crystals; this implies that the drawing imposed by the set collection speed was not sufficient to strongly orient the polymer chains, which is one of the causes of the scarce mechanical properties of these filaments (see par. 3.4). This phenomenon is slightly reduced for fibers collected at $200 \mathrm{~m} / \mathrm{min}$. Nevertheless, once again, this is not fundamental for the application for which these fibers are intended. Remarkably more important is the distribution of the capsules along the fiber and the spinning homogeneity. It can be seen that, in the samples PP-MC10 and PP-MC20, the capsules are homogeneously distributed along the fiber length and they are not aggregated, but in the sample PP-MC30 the diameter is strongly inhomogeneous, which is also appreciable from a visual observation of the spun fibers. This effect, which is more evident with an increase in the collection speed, prevents a consistent characterization of the fibers mechanical properties (see par. 3.4).

Additional information on the fiber diameters and morphology can be derived from the filament cross sections, presented in Figure 3. The PP fibers have a regular circular cross section, while the profile of the PP-MC fibers is irregular and presents lumps in correspondence of the capsules. The capsules appear homogeneously distributed in the cross section, and they are visible as defined domains; and their coreshell structure is clearly visible at high magnifications, which suggests that their integrity is preserved during spinning. As presented in Figure 3f, the fiber diameter decreases with increasing collection speed, but it is not significantly different for fibers containing different amounts of capsules, at a fixed collection speed. What is remarkably affected from the $\mathrm{MC}$ content is the uncertainty of the measurements, as the standard deviation increases with the fraction of capsules. These results also confirm that smaller capsules could help to obtain more regular filaments. However, smaller capsules generally have a lower core-to-shell mass ratio, and thus a lower overall phase change enthalpy, and for the intended application it is not desirable to maximize the fiber homogeneity and the mechanical properties at the expenses of the TES performance.

\subsection{Physical properties}

Table 1 reports the results of the density measurements. The density of the neat PP resulted as $0.8654 \mathrm{~g} / \mathrm{cm}^{3}$, while the bulk density of the microcapsules is $0.9425 \mathrm{~g} / \mathrm{cm}^{3}$, slightly higher than that of the $\mathrm{PP}$ and in good agreement with the nominal value reported on the datasheet $\left(0.9 \mathrm{~g} / \mathrm{cm}^{3}\right)$. Such similarity 


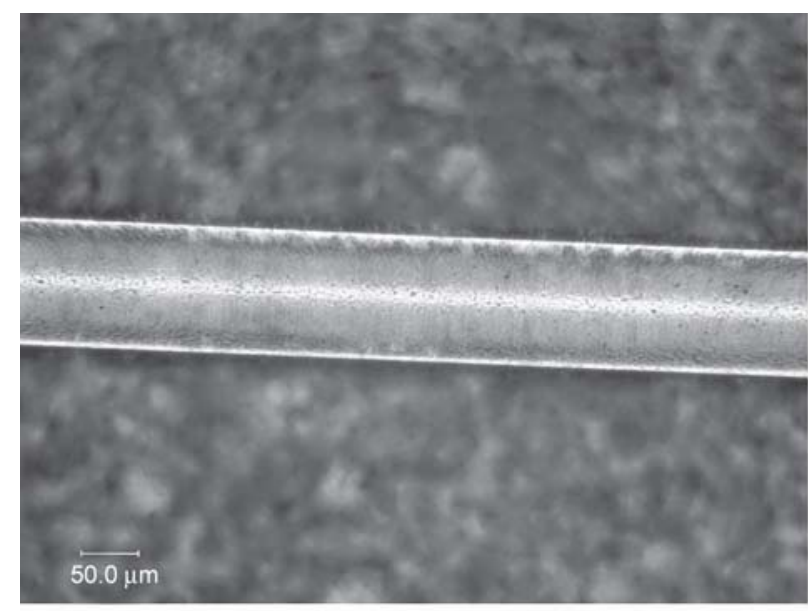

a)

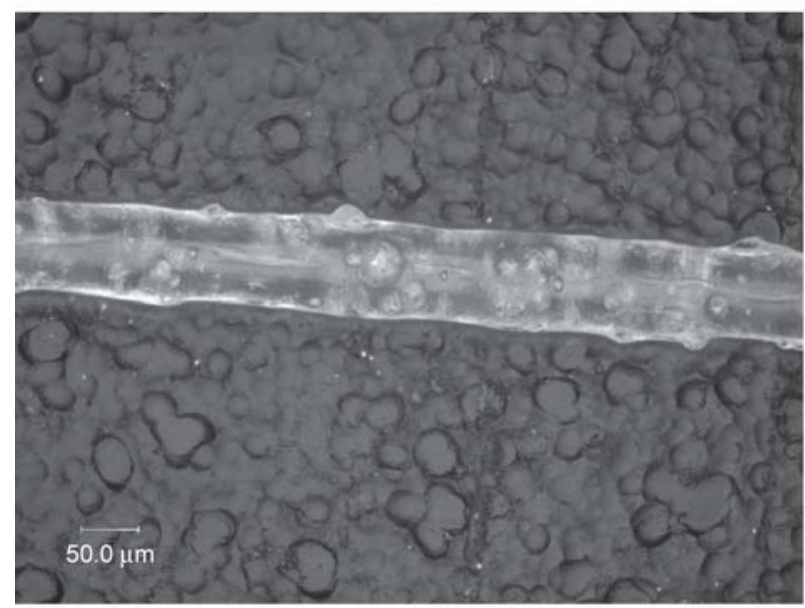

c)

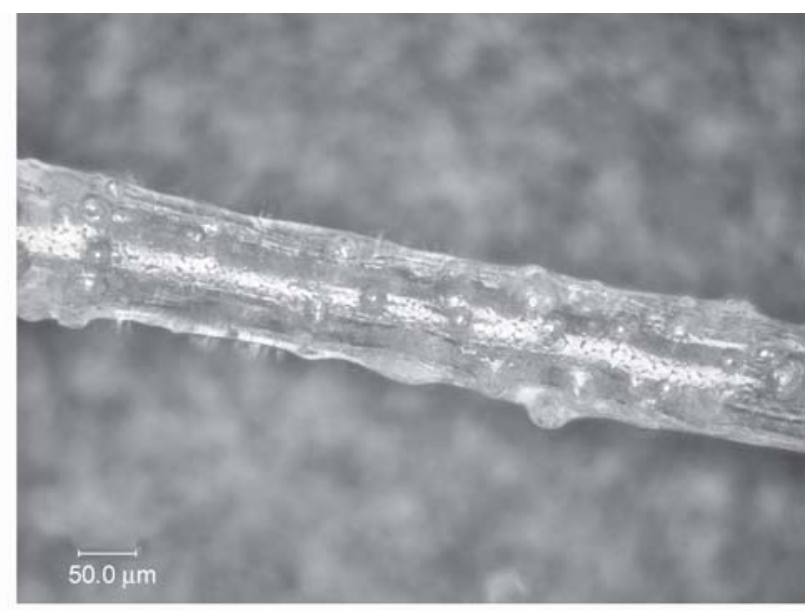

b)

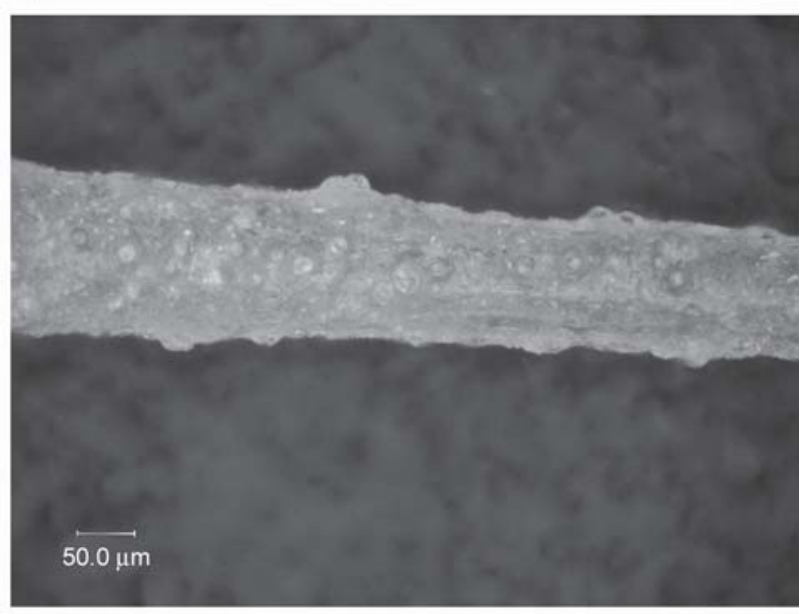

d)

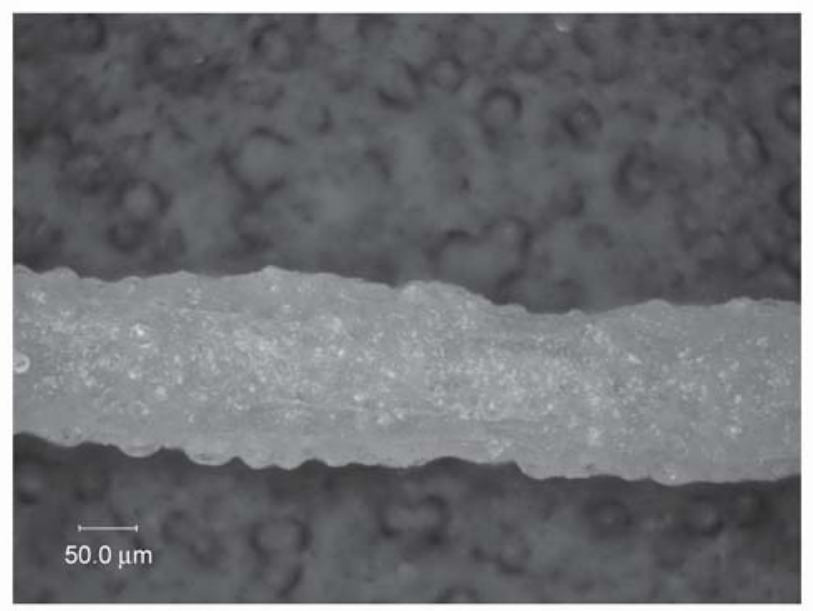

e)

Figure 1. Optical microscope images of the lateral surfaces of the as-spun filaments. The collection speed is reported in brackets: (a) PP (100 m/min); (b) PP-MC10 (100 m/min); (c) PP-MC10 (200 m/min); (d) PP-MC20 (100 m/min); (e) PP-MC30 (100 m/min).

in density is an advantage in the preparation of mixtures, as it favors a more homogeneous dispersion and prevents phase separation. The calculated density and capsule volume fraction of the mixtures are also reported in Table 1 . The density values calculated via the Equation (2) were compared with those measured on some selected compositions, namely the filaments PP-MC10-f, PP-MC20-f and PP-MC30-f collected at $100 \mathrm{~m} / \mathrm{min}$. Their density resulted as $0.8698 \pm 0.0005,0.8805 \pm 0.0004$, and $0.8938 \pm 0.0004 \mathrm{~g} / \mathrm{cm}^{3}$, respectively, in good agreement with the calculated values reported in Table 1. These values were useful to calculate the elastic modulus from the measured fineness and the stress 


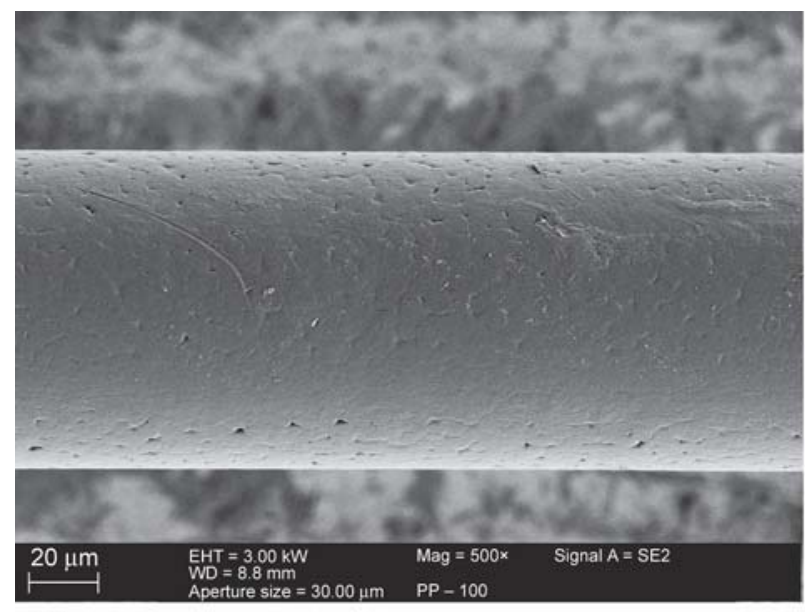

a)

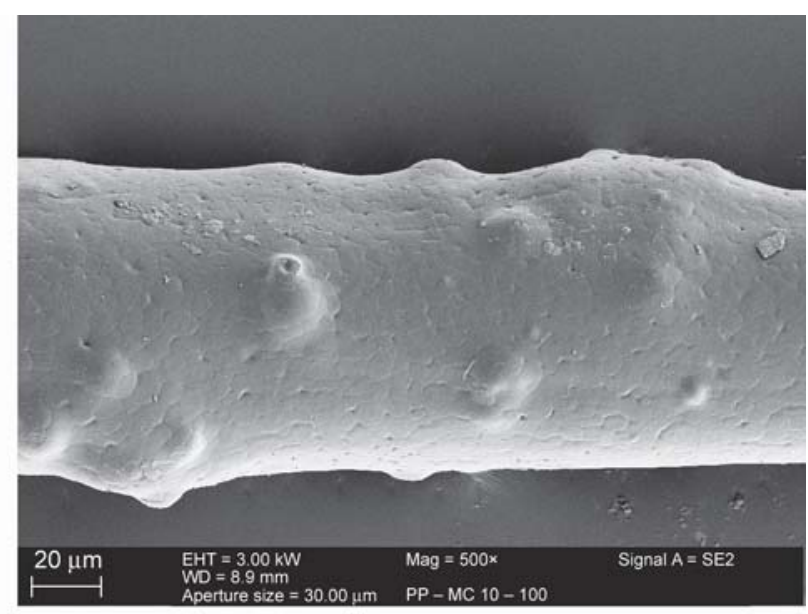

b)

Figure 2. SEM micrographs of the lateral surface of the as-spun filaments, collected at $100 \mathrm{~m} / \mathrm{min}$. (a) PP; (b) PP-MC10.

Table 1. Results of the density measurements on PP and MC and calculation of the MC volume fraction and density for the samples PP-MCx $(\mathrm{x}=10,20,30)$.

\begin{tabular}{|l|c|c|}
\hline & $\begin{array}{c}\text { Density } \\
{\left[\mathbf{g} / \mathbf{c m}^{\mathbf{3}}\right]}\end{array}$ & $\begin{array}{c}\text { MC } \\
{[\mathbf{v o l} \%]}\end{array}$ \\
\hline $\mathrm{PP}$ & $0.8654 \pm 0.0001$ & 0 \\
\hline $\mathrm{MC}$ & $0.9425 \pm 0.0014$ & 100 \\
\hline PP-MC10 & $0.8731 \pm 0.0001$ & $0.0925 \pm 0.0004$ \\
\hline PP-MC20 & $0.8807 \pm 0.0002$ & $0.1867 \pm 0.0006$ \\
\hline PP-MC30 & $0.8885 \pm 0.0003$ & $0.2824 \pm 0.0007$ \\
\hline
\end{tabular}

values reported in $\mathrm{cN} / \mathrm{tex}$ (see par. 3.4), and to obtain values of the diameters that can be compared to those acquired from the $\mathrm{OM}$ analysis.

To assess the effect of the microcapsules on the rheological behavior of the melt PP, dynamic rheological tests were performed on the compounded mixtures. The trend of the complex viscosity is presented in Figure 4a. All the compositions show a behavior typical of non-Newtonian fluids, as their complex viscosity decreases with increasing shear rate, and this shear-thinning effect is stronger at high shear rates. As expected, the complex viscosity increases with increasing $\mathrm{MC}$ content, and this effect is more evident at lower shear stresses, as also reported in the literature for microfilled polymer composites [56, 57], and observed for other thermoplastic polymers filled with paraffin microcapsules [27]. The neat PP presents a Newtonian plateau at low frequencies and a noticeable shear-thinning zone above approx. $30 \mathrm{rad} / \mathrm{s}$. This behavior is observed also in the MC-filled samples containing up to $10-15 \mathrm{wt} \%$ of microcapsules. Above this MC content, the viscosity increase at the lowest limit of the considered shear rate interval implies the presence of a yield stress. This is commonly reported for highly-filled polymer microcomposites, and it is normally attributed to an increased particleparticle interaction and the creation of a filler network [58]. As the MC fraction increases, the transition from the Newtonian plateau to the shear-thinning region is broadened and anticipated to lower shear rates, and the steepness of the power law region increases. These trends are consistent with those reported in the literature for micro- and nanofilled composites [59, 60].

An attempt was made to fit the experimental data with the Carreau model [61, 62], as it is one of the most common models to represent the rheological behavior of polymer melts. The model is described in the Equation (3):

$\frac{\eta_{\dot{\gamma}}-\eta_{\infty}}{\eta_{0}-\eta_{\infty}}=\left(1+|t \dot{\gamma}|^{\mathrm{a}}\right)^{\frac{n-1}{a}}$

where $\eta_{\dot{\gamma}}$ is the value of viscosity at a specific shear rate, $\eta_{0}$ and $\eta_{\infty}$ is the viscosity at zero and infinite shear rate, respectively, $t$ is a time constant, $n$ is the power law or flow index, which accounts for the shear thinning behavior, and $a$ is related to the width of the transition region between the Newonian plateau and the power law region [61]. The results of the fit are reported in Figure 4a. This model fits well the experimental data up to a MC content of $15 \mathrm{wt} \%$, above which it fails in predicting the experimental trend, especially at the limits of the investigated frequency range. This happens because the Carreau model does not consider the rise in viscosity at lower shear stresses, which implies the presence of a yield stress that must be overcome to initiate the flow. The Carreau model can be modified by adding a term that includes the yield stress, according to the model presented by Poslinski et al. [60], reported in Equation (4): 


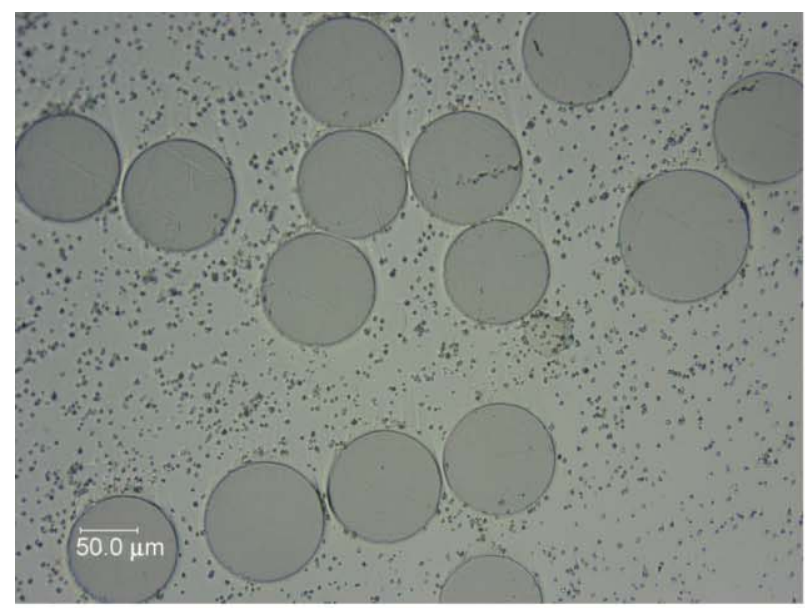

a)

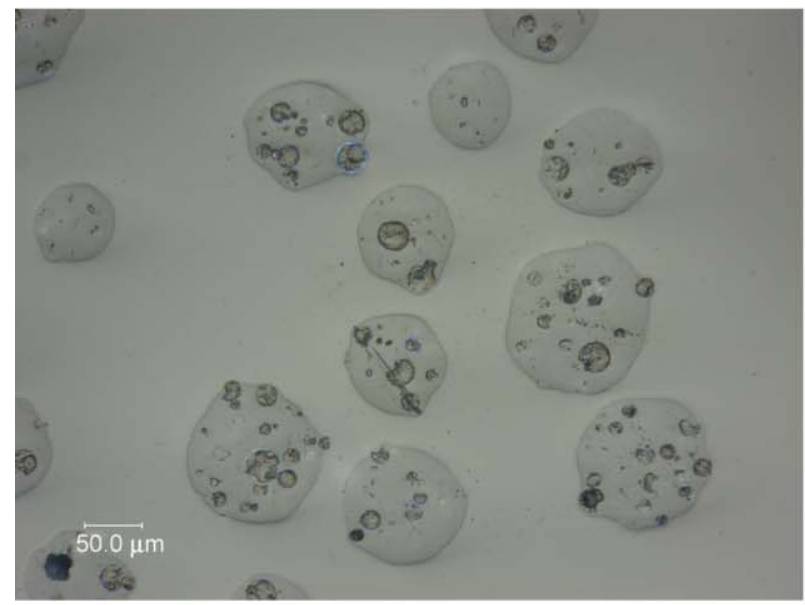

c)

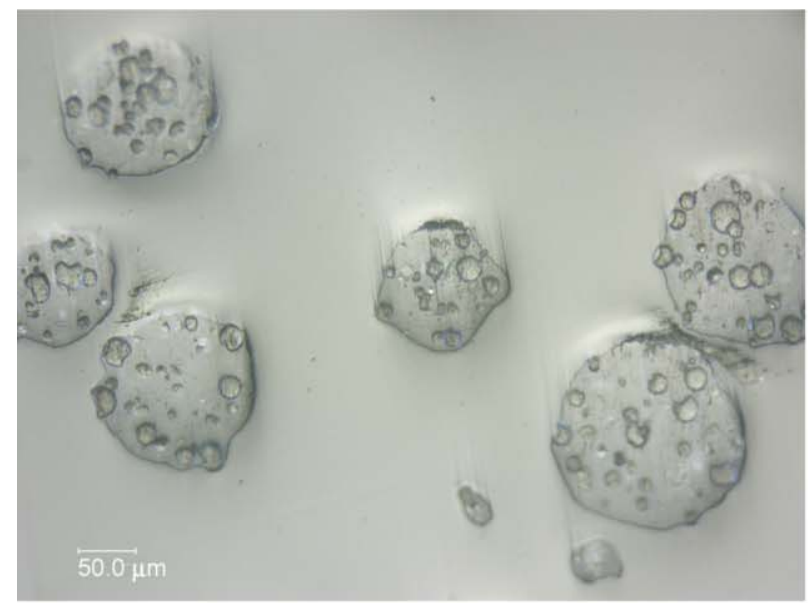

e)

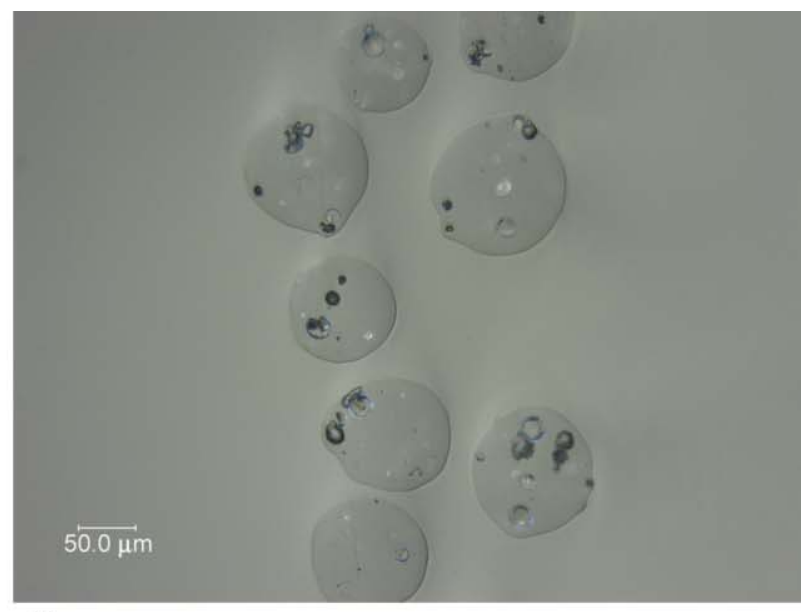

b)

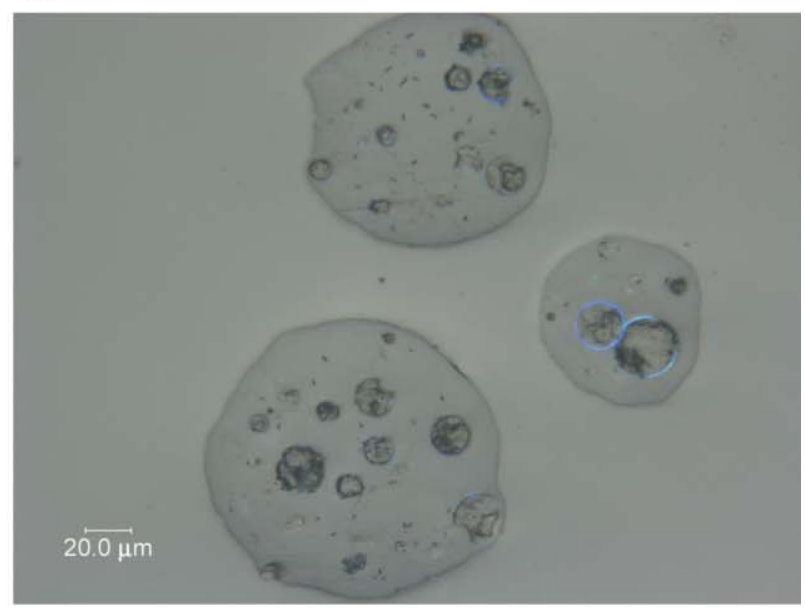

d)

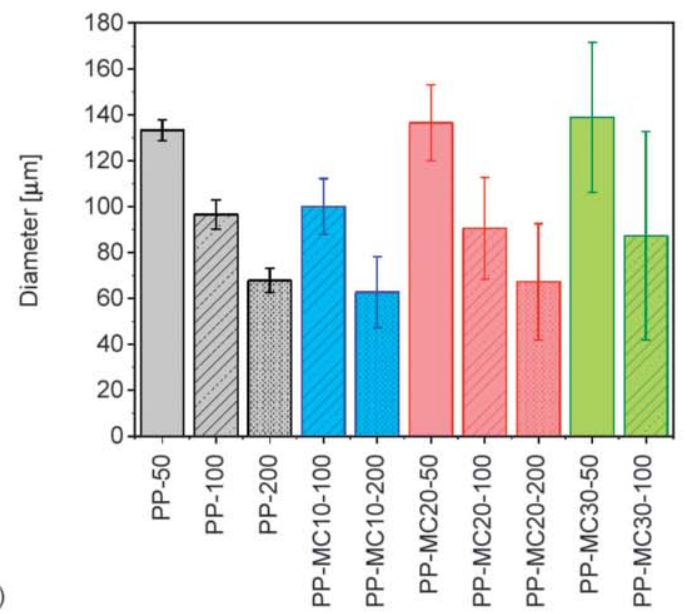

Figure 3. Optical microscope images of the polished cross section of the as-spun filaments, collected at $100 \mathrm{~m} / \mathrm{min}$. (a) PP; (b) PP-MC10; (c) PP-MC20; (d) PP-MC20 (higher magnification); (e) PP-MC30; (f) diameters measured on the cross section.

$\frac{\eta_{\dot{\gamma}}-\eta_{\infty}}{\eta_{0}-\eta_{\infty}}=\frac{\tau_{0}}{\dot{\gamma}}+\left(1+|t \dot{\gamma}|^{a}\right)^{\frac{n-1}{a}}$

where $\tau_{0}$ is the yield stress and the other parameters have the same values as for Equation (3). In the present work, a is a free parameter, unlike in the model presented by Poslinski et al. [60], where a was kept equal to 2 as in the former Carreau model. Figure $4 \mathrm{a}$ reports also the results of the fitting with this model. With the additional term, the fitting for the highly concentrated samples improves considerably. Figure $4 \mathrm{~b}$ reports the trends of $\eta_{0}$ and $\tau_{0}$ obtained from the fit, presented with their standard error. Both parameters increase with an increase in the $\mathrm{MC}$ weight 

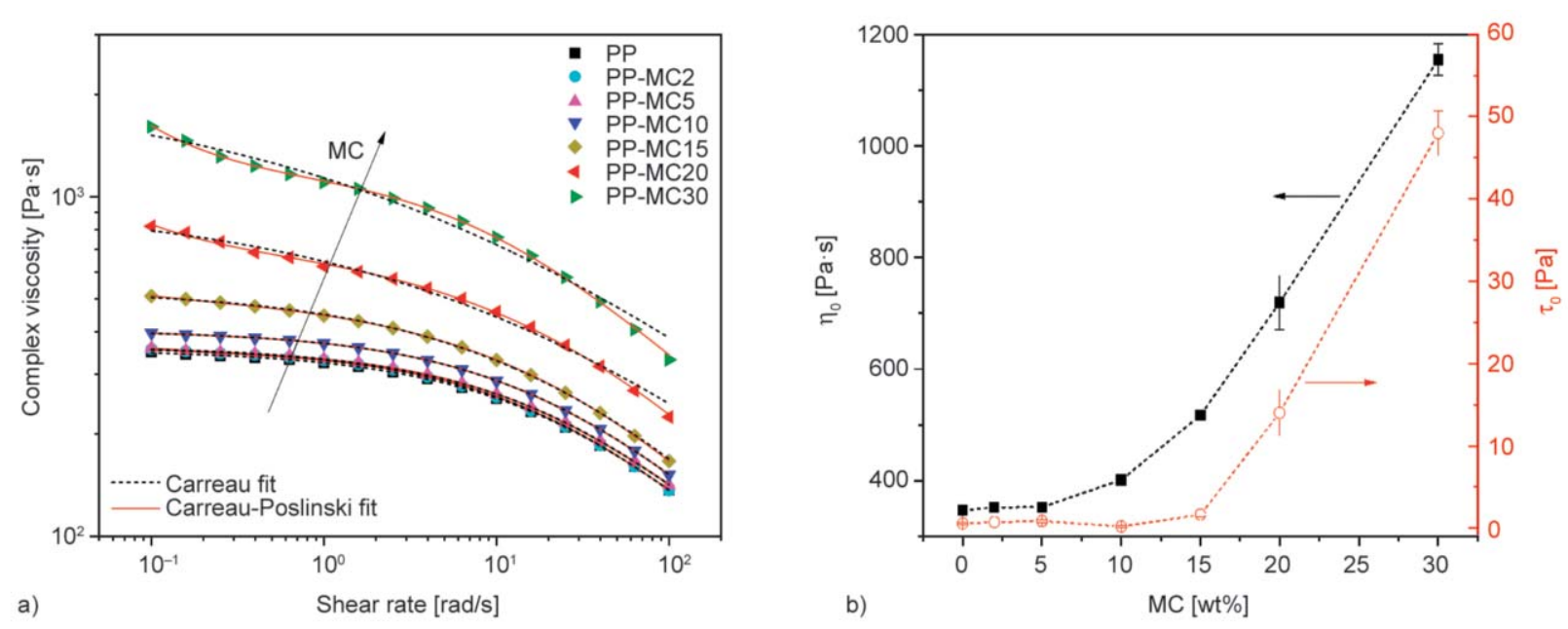

Figure 4. (a) Complex viscosity as a function of the shear rate for the compounded samples PP and PP-MCx $(\mathrm{x}=2,5,10$, 15, 20,30), with the results of the fitting with the Carreau and the Carreau-Poslinski model; (b) Parameters derived from the fitting with the Carreau-Poslinski model: zero-shear viscosity $\left(\eta_{0}\right)$ and yield stress $\left(\tau_{0}\right)$ as a function of the $\mathrm{MC}$ weight fraction.

fraction, and the value of $\tau_{0}$ is significantly higher than 0 for a $\mathrm{MC}$ concentration higher than $15-20 \mathrm{wt} \%$, which explains the suitability of the unmodified Carreau model to fit the experimental data for the less concentrated compositions. Figure 5 reports the trends of the storage modulus $G^{\prime}$, the loss modulus $G^{\prime \prime}$, and the $\tan \delta$ as a function of the applied shear rate. The increase in $G^{\prime}$ and $G^{\prime \prime}$ with the MC content is more marked at lower shear rates, and especially the trend of $G^{\prime}$ evidences the presence of a yield stress for the highly filled compositions. On the other hand, the values of $\tan \delta$ decreases with an increase in the MC fraction, and the shape of the trend differs sensibly from that of the neat PP for MC loadings higher than $15 \mathrm{wt} \%$.

\subsection{Thermal properties}

One of the most important properties that these PCM-enhanced fibers must feature is a high phase change enthalpy, which depends on the effective PCM weight fraction at the end of the processing. This was assessed through DSC tests, performed to evaluate the TES properties at the end of each processing step, namely the melt compounding and the melt spinning. The DSC thermograms obtained on the filaments collected at $100 \mathrm{~m} / \mathrm{min}$ are reported in Figure $6 \mathrm{a}$, while Figure $6 \mathrm{~b}$ shows the first heating scan of the filaments and the compounded samples and reports the melting enthalpy values and the peak temperatures. For all the samples reported in Figure $6 \mathrm{a}$, the heating scan presents two main endothermic signals: the first at $40-50^{\circ} \mathrm{C}$, related to the PCM melting, and the second at $140-160^{\circ} \mathrm{C}$, associated to the melting of PP. The cooling scan shows the exothermic signals associated to the crystallization of the two phases, at $30-40$ and $110-130^{\circ} \mathrm{C}$, respectively. For the PMC phase change, the signals show two main peaks, which resemble those visible in the DSC thermogram of the neat MC. As already observed by our group [20, 22, 23] and elsewhere in the literature [63] for several types of paraffin-based PCMs with similar phase change temperatures, the presence of two or more peaks derive from a sequence of transitions on heating and cooling. The first smaller peak encountered on heating could be related to the solid-solid transition from the crystalline phase to the so-called 'rotator phase', while the second peak could be ascribed to the solid-liquid transition, and the same is observable on cooling. This explanation is in good agreement with the detailed investigation performed by Wang et al. [63] on the thermal transitions of $n$-docosane $\left(\mathrm{C}_{22} \mathrm{H}_{46}\right)$, which has approximately the same melting temperature as the PCM object of this work. However, since all the mentioned transitions contribute to the total phase change enthalpy and happen in a relatively narrow temperature range, the precise assignment of each peak found the DSC spectra is out of the scope of this work, and it would be also quite troublesome, as the PCM contained in the microcapsules is probably an alkane mixture and the precise molecular weight distribution has not been measured. As reported in Figure $6 \mathrm{~b}$ and in Table 2, the enthalpy of the PCM phase change increases with the nominal MC content. Considering that the phase change enthalpy measured on the neat MC is $208.0 \mathrm{~J} / \mathrm{g}$, the enthalpy 
of the filaments is lower than expected considering the nominal PCM content, being approx. $70 \%$ of the

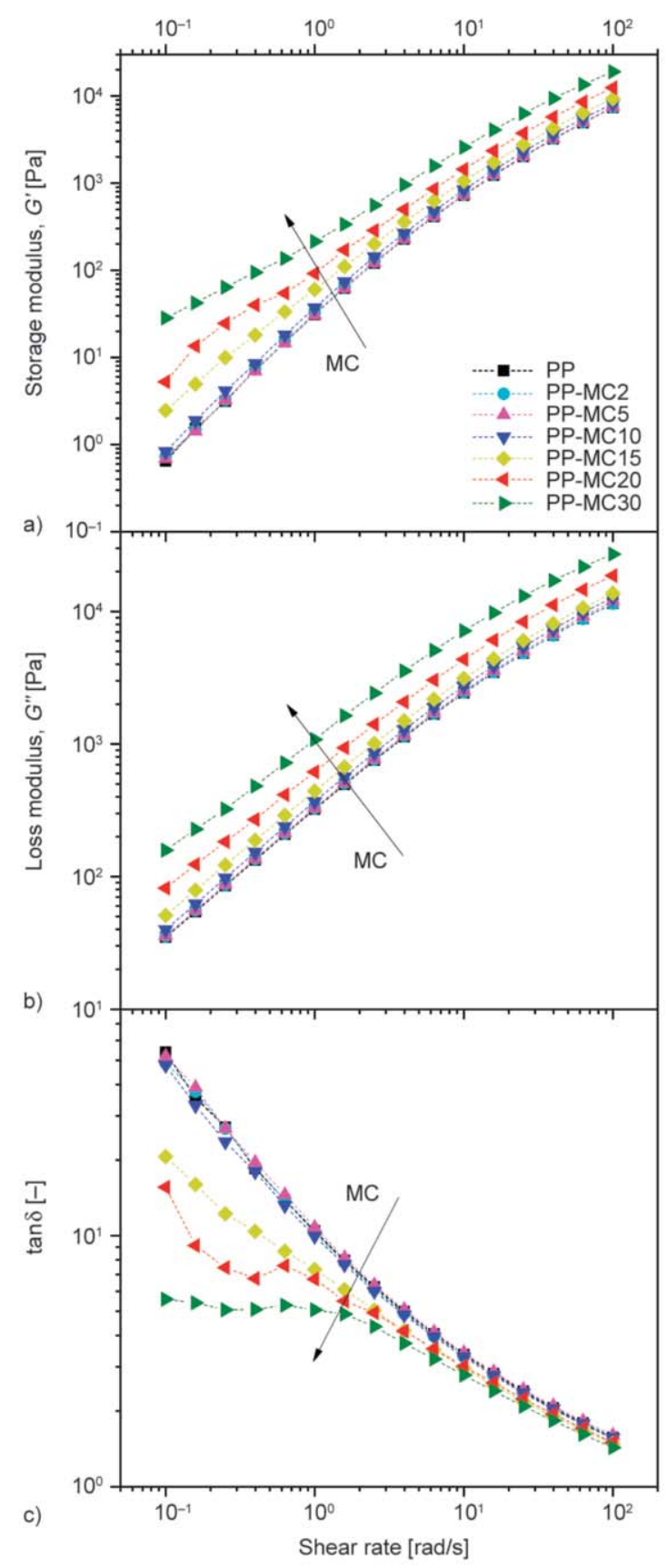

Figure 5. a) Storage modulus $G^{\prime}$, b) loss modulus $G^{\prime \prime}$ and c) $\tan \delta$ as a function of the shear rate for the compounded samples PP and PP-MCx $(\mathrm{x}=2,5,10$, $15,20,30)$. expected value, as detailed in Table 2. From the measured enthalpy data, an experimental residual PCM weight fraction can be calculated for each sample, by applying an approach similar to that reported by Rezaie et al. [64]; these data are also presented in Table 2. It can be observed that the PCM mass fraction measured at the end of the process is lower than the initial one. This very probably derives from the mechanical and thermal degradation of the PCM during processing and could be alleviated by choosing milder processing parameters. It is important to understand which processing step is the main responsible for the PCM degradation, and this was evaluated through a comparison between the DSC scans of the filaments and the compounded mixtures, reported in Figure 6b, where also the signal of the neat $\mathrm{MC}$ is reported for comparison. The signals of the filaments are sharper and their peak temperatures (reported on the graph) are slightly lower than those of their corresponding compounded mixtures. This could be due to the different specimen geometry, which may have influenced the contact with the crucible and the heat transfer during the test even though the specimen mass was the same. However, the melting enthalpy of the filaments is nearly the same (never less than the $88 \%$ ) as that developed by the compounded mixtures, which implies that the majority of the PCM degradation happens during the melt compounding. Therefore, although the employed PP has a considerably low viscosity, the shear stresses developed during compounding are sufficient to mechanically damage a not negligible fraction of microcapsules. This effect was observed also on microcapsules/polyamide 12 mixtures prepared via melt compounding [27]. The situation could be improved by using microcapsules with a mechanically stronger shell, or by changing the compounding parameters to reduce the shear stresses. On the other hand, the enthalpy loss during melt spinning is almost negligible, which suggests that the parameters adopted in this process are mild enough to preserve the microcapsule integrity and the initial PCM fraction.

Table 2. Expected and measured melting enthalpy and nominal and experimental PCM content in the prepared filaments (samples PP-MCx-f, $\mathrm{x}=10,20,30$ ).

\begin{tabular}{|l|c|c|c|c|c|}
\hline & $\begin{array}{c}\text { Nominal PCM content } \\
{[\mathbf{w t} \%]}\end{array}$ & $\begin{array}{c}\text { Expected enthalpy } \\
{[\mathbf{J} / \mathbf{g}]}\end{array}$ & $\begin{array}{c}\text { Measured enthalpy } \\
{[\mathbf{J} / \mathbf{g}]}\end{array}$ & $\begin{array}{c}\text { Relative enthalpy } \\
{[\mathbf{\%}]}\end{array}$ & $\begin{array}{c}\text { Experimental PCM } \\
\text { content }\end{array}$ \\
\hline PP-MC10-f & 10 & 20.8 & 13.9 & 66.8 & 6.7 \\
\hline PP-MC20-f & 20 & 41.6 & 28.3 & 68.0 & 13.6 \\
\hline PP-MC30-f & 30 & 62.4 & 47.5 & 76.1 & 22.8 \\
\hline
\end{tabular}



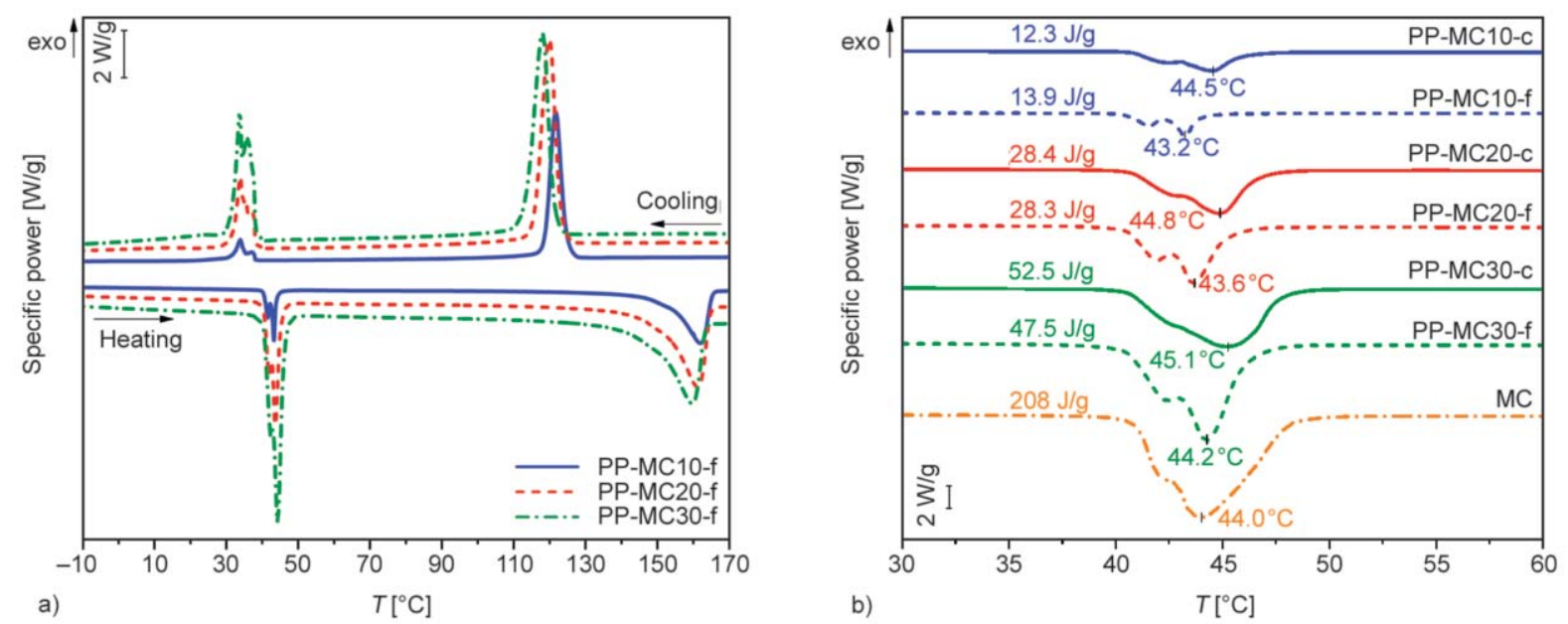

Figure 6. (a) DSC thermograms of the filaments containing microcapsules, collected at $100 \mathrm{~m} / \mathrm{min}$ (first heating scan and cooling scan). (b) PCM melting peaks of the compounded mixtures and the filaments $(100 \mathrm{~m} / \mathrm{min}$ ) containing capsules. The plot reports the peak temperatures and the melting enthalpies. The thermogram of the neat MC is also reported for comparison.

The reduction in the specific enthalpy compared to the nominal one can be also attributed to the fact that a fraction of PCM has leaked out of the microcapsules and is dissolved within the PP phase, which prevents the single PCM chains from crystallizing properly and contributing to the total developed phase change enthalpy [65]. This aspect could be evaluated through TGA, which allows estimating the weight fraction of the different constituents. TGA tests were performed also to assess the thermal stability of the virgin materials, the compounded mixtures and the filaments. The results of this investigation are reported in Figure 7 and in Table 3. The virgin PP degrades in a single step at approx. $450^{\circ} \mathrm{C}$, and the same behavior is observed also on the PP filament, which suggests that the spinning step does not decrease the thermal stability of PP. Conversely, the thermal degradation of the microcapsules begins with several small subsequent steps. The mass loss at lower temperature can be related to free (non-encapsulated) paraffin and some low molecular weight compounds, present as residuals of the capsule synthesis, while the subsequent steps are related to the thermal degradation of the paraffin and the melamine-formaldehyde shell. Previous works [20] showed that a non-encapsulated paraffin wax with a molecular weight similar to that of this PCM is completely degraded at already $250^{\circ} \mathrm{C}$, which suggests that the encapsulation contributes also to the thermal stability. The sharp peak in the mass loss derivative signal indicates that most of the mass loss happens in a relatively narrow temperature interval. This mass loss can be associated to the damage of the microcapsule shell and the sudden release of the PCM core. This spike was observed also on the repeated measurement, but it is not observed in any of the PCM-containing composites, as the presence of the surrounding matrix may modify the mass loss rate. The degradation curves of the compounded mixtures and the spun filaments consist in an initial mass loss step $\left(200-300^{\circ} \mathrm{C}\right)$, which increases with the $\mathrm{MC}$ content, followed by a second step $\left(400-500^{\circ} \mathrm{C}\right)$ corresponding to the degradation of the PP phase. Generally speaking, the thermal stability of the blends decreases with an increase in the MC content, as the MC phase is less thermally stable then the PP, which is observable both on the trend of the mass loss (Figure 7) as an anticipation in the degradation onset, and on the data reported in Table 3.

Table 3. Main results of the TGA tests on the virgin, as-compounded and as-spun samples.

\begin{tabular}{|l|c|c|c|c|}
\hline & $\begin{array}{c}\boldsymbol{T}_{\mathbf{1} \%} \\
{\left[{ }^{\circ} \mathbf{C}\right]}\end{array}$ & $\begin{array}{c}\boldsymbol{T}_{\mathbf{3} \%} \\
{\left[{ }^{\circ} \mathbf{C}\right]}\end{array}$ & $\begin{array}{c}\boldsymbol{T}_{\mathbf{5} \%} \\
{\left[{ }^{\circ} \mathbf{C}\right]}\end{array}$ & $\begin{array}{c}\boldsymbol{T}_{\mathbf{d}} \\
{\left[{ }^{\circ} \mathbf{C}\right]}\end{array}$ \\
\hline PP-neat & 359.5 & 395.8 & 407.7 & 450.8 \\
\hline PP-f & 335.3 & 384.8 & 402.5 & 450.7 \\
\hline PP-MC10-c & 205.0 & 302.0 & 361.7 & 444.3 \\
\hline PP-MC10-f & 197.0 & 324.4 & 361.6 & 442.4 \\
\hline PP-MC20-c & 169.3 & 207.6 & 231.2 & 442.8 \\
\hline PP-MC20-f & 153.7 & 198.2 & 276.5 & 443.4 \\
\hline PP-MC30-c & 155.7 & 189.2 & 208.3 & 440.6 \\
\hline PP-MC30-f & 148.3 & 193.3 & 271.0 & 443.0 \\
\hline MC & 125.3 & 164.0 & 235.3 & 402.6 \\
\hline
\end{tabular}

$T_{1 \%}, T_{3 \%}, T_{5 \%}=$ temperatures corresponding to a mass loss of 1,3 and 5. $T_{\mathrm{d}}=$ peak temperature of the mass loss derivative. 

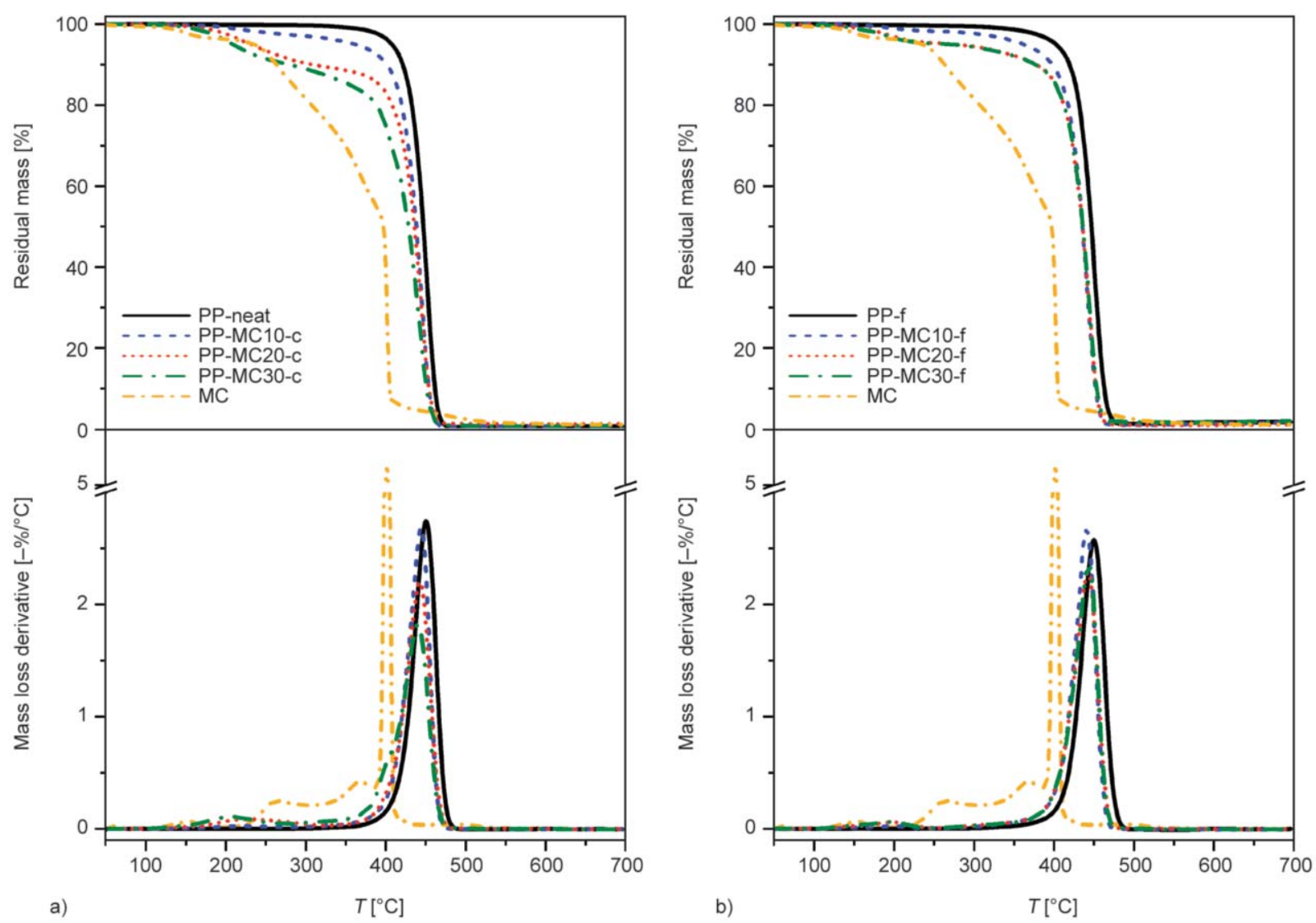

Figure 7. TGA thermograms of the as-compounded (a) and the as-spun samples (b). Residual mass and mass loss derivative as a function of temperature.

It can be additionally observed that, for the samples PP-MC20 and PP-MC30, the initial mass loss is significantly higher for the compounded samples than for the filaments. This suggests that the filaments contain less PCM than the compounded specimen, but the almost negligible decrease in melting enthalpy after spinning (see Figure $6 \mathrm{~b}$ ) seems to contradict this hypothesis. This effect can be explained by considering that the compounding step causes the breakage of a consistent fraction of microcapsules, but a fraction of the leaked paraffin does not degrade but dissolves in the PP matrix. As observed in other studies $[20,65]$, the presence of the surrounding matrix could prevent this PCM fraction to properly crystallize, and therefore it does not contribute to the total phase change enthalpy measured by DSC. Since it is not protected by the MC shell, the free paraffin fraction degrades at low temperatures and could also partially degrade during the spinning step.

These TGA tests have been useful to investigate the temperatures of thermal degradation of the materials. However, a complete thermal analysis must ensure that the materials do not degrade during processing: the thermal history applied during melt compounding and melt spinning is more complex than a temperature ramp, and it is important to consider the residence times at certain temperatures during the compounding and spinning steps. Thus, isothermal TGA tests were performed on the neat PP and MC, as well as on the three compounded mixtures, at three different temperatures. The results of this investigation are reported in Figure 8 and Table 4. As expected, the neat PP experiences a negligible mass loss in the investigated time span for all the considered temperatures. The neat MC undergo an initial mass loss of approx. 3-4 wt $\%$, as happens in the TGA ramp tests. The mass is subsequently stable over time for all the considered temperatures, which agrees with the results of the ramp TGA tests and the indication of the thermal stability provided in the datasheet. This suggests that the chosen microcapsules can withstand the temperatures required to process a polymer melt better than most of the non-encapsulated organic PCMs reported in the literature [20, 40, 66-68]. On the other hand, the behavior of the compounded mixtures deviates significantly from this trend, as the mass loss increases with time, applied temperature and $\mathrm{MC}$ concentration, without reaching a plateau. 
As the PP phase has proven to be thermally stable, the mass loss can be related to the free paraffin released from the capsules broken during compounding. This indicates that the mechanical stresses during compounding are the main cause of the decreasing thermal stability of the microcapsules, which must be taken into account during the setting of the melt spinning parameters, and suggests that a milder compounding could be useful in preserving the capsule integrity and the overall thermal stability. Nevertheless, the mass loss at the chosen spinning temperature $\left(180^{\circ} \mathrm{C}\right)$ and after the maximum residence time during spinning (10 min) is between 1 and $3 \mathrm{wt} \%$, which proves the suitability of the chosen processes and parameters.

Table 4. Mass loss after 10 minutes in the isothermal TGA tests on the compounded samples.

\begin{tabular}{|l|c|c|c|}
\hline & $\mathbf{1 8 0}^{\circ} \mathbf{C}$ & $\mathbf{1 9 0}^{\circ} \mathbf{C}$ & $\mathbf{2 0 0}^{\circ} \mathbf{C}$ \\
\hline MC & 3.53 & 3.87 & 3.93 \\
\hline PP & 0.09 & 0.05 & 0.07 \\
\hline PP-MC10 & 2.03 & 1.52 & 1.80 \\
\hline PP-MC20 & 1.90 & 2.50 & 4.32 \\
\hline PP-MC30 & 3.22 & 5.09 & 5.26 \\
\hline
\end{tabular}

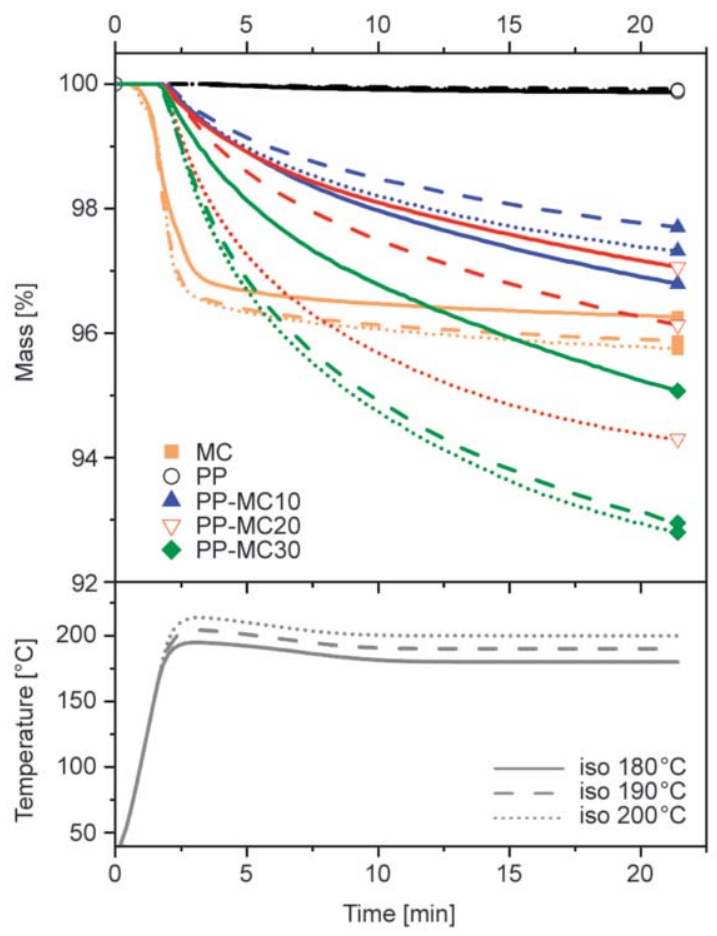

Figure 8. Results of the isothermal TGA tests on the samples PP, MC and as-compounded PP-MCx ( $\mathrm{x}=10,20$, 30). The residual mass and the applied temperature profiles are reported as a function of time. Solid lines $=$ test at $180^{\circ} \mathrm{C}$; dashed lines $=$ test at $190^{\circ} \mathrm{C}$; dotted lines $=$ test at $200^{\circ} \mathrm{C}$.

\subsection{Mechanical properties}

The main results of the single-fiber tensile tests are reported in Figure 9. As the tensile testing apparatus directly measures the fineness of each tested fiber, the stress values are reported in $\mathrm{cN} / \mathrm{tex}$, a common practice for fibers and filaments. The filaments containing $30 \mathrm{wt} \%$ of $\mathrm{MC}$ could not be tested, as they always broke before the test or in the preload phase, which is probably related to the strongly inhomogeneous cross section (see par. 3.1). The neat PP fibers collected at $50 \mathrm{~m} / \mathrm{min}$ (PP-50) could not be tested until failure, as their elongation at break was higher than the maximum displacement allowed by the testing device, and thus the values of strain at break and tenacity reported in Figure 9 refer to the last measured point in the stress-strain curve.

It can be observed that the fineness decreases with increasing collection speed, but it is not significantly different for fibers containing different amounts of MC collected at the same speed. The MC addition dramatically changes the stress-strain behavior of the PP. The tenacity of the fibers increases with the collection speed, due to a higher chain orientation, but it decreases with an increase in the MC content. For example, the neat PP fibers collected at $100 \mathrm{~m} / \mathrm{min}$ exhibit a tenacity of $7.0 \pm 0.4 \mathrm{cN} /$ tex, while for the sample PP-MC20-100 the value of tenacity is 33\% of the original value, being $2.3 \pm 0.5 \mathrm{cN} /$ tex. The elongation at break also decreases with increasing collection speed and $\mathrm{MC}$ concentration. It can be noticed that the tenacity of these fibers is rather low and the elongation at break considerably high if compared

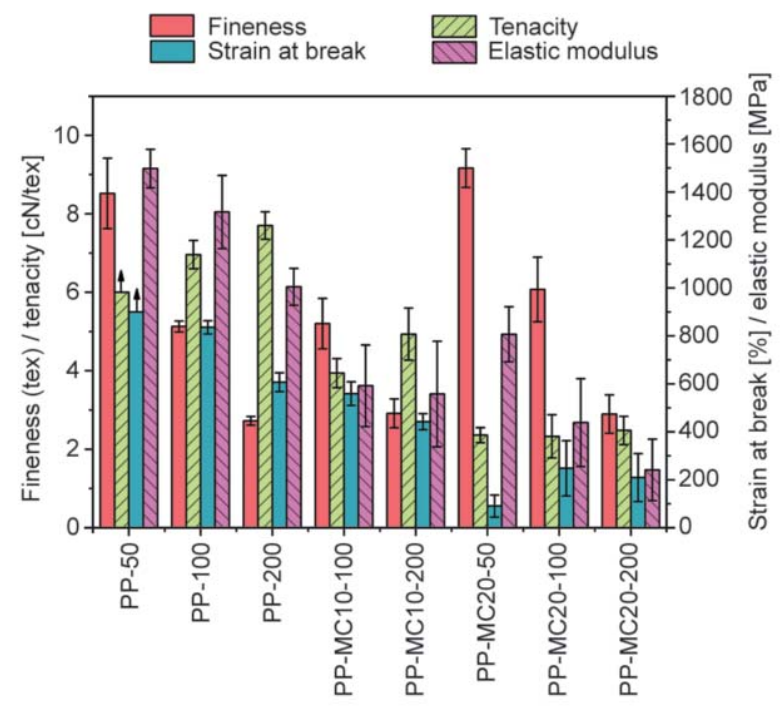

Figure 9. Main parameters obtained from the single-fiber tensile test. 
to other polymer fibers for textile applications [69], which is likely due to the fact that the limited draw ratio is not sufficient to orient the polymer chains along the fiber axis. The values of density reported in Table 1 were employed to calculate the filament diameters from the fineness values measured by the tensile testing machine. As these values were not significantly different from those measured with the optical microscope (Figure 3f), the values of density were employed to calculate the elastic modulus in $\mathrm{MPa}$, reported in Figure 9. The elastic modulus is also negatively affected by an increasing content of MC. The reduction in the mechanical performance of filaments after the addition of a PCM is a common phenomenon reported elsewhere in the literature [ 40 , 70] and could be partially solved by a post-drawing process [40], or by employing smaller microcapsules or narrowing the particle size distribution [71]. However, as these filaments are intended for the production of hybrid yarns and not for further textile processing, the mechanical properties are not of the outermost importance and their improvement is out of the scope of this work.

\section{Conclusions}

PCM-enhanced polypropylene filaments were successfully produced via small-scale melt compounding and piston-type melt spinning devices, and the subsequent characterization of the physical, thermal and mechanical properties demonstrated their suitability for the production of multifunctional hybrid yarns where they are considered to serve as polymer matrix. The melt compounding step proved itself fundamental to achieve a homogeneous distribution of $\mathrm{MC}$ in the PP matrix, for all the investigated compositions ( $\mathrm{MC}$ content $=10,20$ and $30 \mathrm{wt} \%$ ), and the characterization of the as-compounded mixtures gave important information, preliminary to the melt spinning step. The rheological characterization of the ascompounded mixtures highlighted that the increase in the complex viscosity with the MC content is more pronounced at low shear rates, and increasingly less evident while approaching the shear rates typically applied in a melt spinning process. Isothermal TGA on the neat PP and MC revealed that their thermal stability is sufficiently high to withstand the applied processing temperatures, but the same test on the as compounded mixtures showed a not negligible mass loss, which is due to the degradation of the PCM leaked out from those microcapsules that were damaged during compounding. Nevertheless, the mass loss after 10 minutes, which is the maximum residence time in the spinning chamber, is still acceptably low (below $5.3 \mathrm{wt} \%$ ), which indicates that the compounding parameters were mild enough to preserve the integrity of a considerable fraction of MC. For the characterization of the filaments, microscopy techniques highlighted that the inclusion of MC increased the filament surface roughness, but it did not significantly influence the diameter, which varied in the range $70-140 \mu \mathrm{m}$ according to the collection speed. DSC tests revealed that the melting enthalpy increases with an increasing $\mathrm{MC}$ fraction, up to $48 \mathrm{~J} / \mathrm{g}$, while single-filament tensile tests evidenced a decrease in the mechanical properties with an increase in the MC content.

These results are promising for the production of PCM-enhanced hybrid yarns. Future work will involve the use of these MC-containing filaments to produce a thermoplastic laminate via hot compaction, as well as the study of the scalability of the process with the use of a twin-screw extruder and the cowinding with reinforcing fibers to produce hybrid yarns.

\section{Acknowledgements}

Ms. Sabine Krause is acknowledged for performing the thermal analysis tests. Ms. Steffi Pressler is acknowledged for her contribution in the single-fiber tensile tests.

\section{References}

[1] Chilali A., Zouari W., Assarar M., Kebir H., Ayad R.: Analysis of the mechanical behaviour of flax and glass fabrics-reinforced thermoplastic and thermoset resins. Journal of Reinforced Plastics and Composites, 35, 1217-1232 (2016). https://doi.org/10.1177/0731684416645203

[2] Mallick P. K.: Fiber reinforced composites. Materials, manufacturing, and design. Taylor and Francis, Boca Raton (2007).

[3] Biron M.: Thermoplastics and thermoplastic composites. Elsevier, Oxford (2013).

[4] Alagirusamy R., Fangueiro R., Ogale V., Padaki N.: Hybrid yarns and textile preforming for thermoplastic composites. Textile Progress, 38, 1-71 (2006). https://doi.org/10.1533/tepr.2006.0004

[5] Bhudolia S. K., Perrotey P., Joshi S. C.: Enhanced vibration damping and dynamic mechanical characteristics of composites with novel pseudo-thermoset matrix system. Composite Structures, 179, 502-513 (2017). https://doi.org/10.1016/j.compstruct.2017.07.093 
[6] Muthuraj R., Grohens Y., Seantier B.: Mechanical and thermal insulation properties of elium acrylic resin/cellulose nanofiber based composite aerogels. Nano-Structures and Nano-Objects, 12, 68-76 (2017). https://doi.org/10.1016/j.nanoso.2017.09.002

[7] Xu Z., Zhang M., Gao S., Wang G., Zhang S., Luan J.: Study on mechanical properties of unidirectional continuous carbon fiber-reinforced PEEK composites fabricated by the wrapped yarn method. Polymer Composites, 40, 56-69 (2019).

https://doi.org/10.1002/pc.24600

[8] Abounaim M., Diestel O., Offmann G., Cherif C.: High performance thermoplastic composite from flat knitted multi-layer textile preform using hybrid yarn. Composites Science and Technology, 71, 511-519 (2011). https://doi.org/10.1016/j.compscitech.2010.12.029

[9] Spickenheuer A., Scheffler C., Bittrich L., Haase R., Weise D., Garray D., Heinrich G.: Tailored fiber placement in thermoplastic composites. Technologies for Lightweight Structures, 1, 114-127 (2017). https://doi.org/10.21935/tls.v1i2.95

[10] Hsiao P-C., Lin C-M., Lu C-T., Yin W., Huang Y-T., Lin J-H.: Manufacture and evaluations of stainless steel/ rayon/bamboo charcoal functional composite knits. Textile Research Journal, in press (2019). https://doi.org/10.1177/0040517518821904

[11] Cheng K. B., Ramakrishna S., Lee K. C.: Development of conductive knitted-fabric-reinforced thermoplastic composites for electromagnetic shielding applications. Journal of Thermoplastic Composite Materials, 13, 378399 (2000).

https://doi.org/10.1106/mhkx-74a6-pkem-j7pl

[12] Risicato J-V., Kelly F., Soulat D., Legrand X., Trümper W., Cochrane C., Koncar V.: A complex shaped reinforced thermoplastic composite part made of commingled yarns with integrated sensor. Applied Composite Materials, 22, 81-98 (2014).

https://doi.org/10.1007/s10443-014-9400-9

[13] Chen H-C., Lee K-C., Lin J-H.: Electromagnetic and electrostatic shielding properties of co-weaving-knitting fabrics reinforced composites. Composites Part A: Applied Science and Manufacturing, 35, 1249-1256 (2004).

https://doi.org/10.1016/s1359-835x(04)00119-8

[14] Friedrich K.: Routes for achieving multifunctionality in reinforced polymers and composite structures. in 'Multifunctionality of polymer composites' (eds.: Friedrich K., Ulf B.) Elsevier, Waltham, 3-41 (2015). https://doi.org/10.1016/b978-0-323-26434-1.00001-5

[15] Polydoropoulou P. V., Katsiropoulos C. V., Pantelakis S. G., Raimondo M., Guadagno L.: A critical assessment of multifunctional polymers with regard to their potential use in structural applications. Composites Part B: Engineering, 157, 150-162 (2019).

https://doi.org/10.1016/j.compositesb.2018.08.092
[16] Hasnain S. M.: Review on sustainable thermal energy storage technologies, Part I: heat storage materials and techniques. Energy Conversion and Management, 39, 1127-1138 (1998). https://doi.org/10.1016/S0196-8904(98)00025-9

[17] Wang Z., Qiu F., Yang W., Zhao X.: Applications of solar water heating system with phase change material. Renewable and Sustainable Energy Reviews, 52, 645652 (2015).

https://doi.org/10.1016/j.rser.2015.07.184

[18] Dorigato A., Canclini P., Unterberger S. H., Pegoretti A.: Phase changing nanocomposites for low temperature thermal energy storage and release. Express Polymer Letters, 11, 738-752 (2017).

https://doi.org/10.3144/expresspolymlett.2017.71

[19] Cui Y., Xie J., Liu J., Pan S.: Review of phase change materials integrated in building walls for energy saving. Procedia Engineering, 121, 763-770 (2015).

https://doi.org/10.1016/j.proeng.2015.09.027

[20] Fredi G., Dorigato A., Fambri L., Pegoretti A.: Wax confinement with carbon nanotubes for phase changing epoxy blends. Polymers, 9, 405/1-405/16 (2017).

https://doi.org/10.3390/polym9090405

[21] Fredi G., Dorigato A., Fambri L., Pegoretti A.: Multifunctional epoxy/carbon fiber laminates for thermal energy storage and release. Composites Science and Technology, 158, 101-111 (2018).

https://doi.org/10.1016/j.compscitech.2018.02.005

[22] Dorigato A., Fredi G., Pegoretti A.: Application of the thermal energy storage concept to novel epoxy-short carbon fiber composites. Journal of Applied Polymer Science, 136, 47434/1-47434/9 (2019). https://doi.org/10.1002/app.47434

[23] Fredi G., Dirè S., Callone E., Ceccato R., Mondadori F., Pegoretti A.: Docosane-organosilica microcapsules for structural composites with thermal energy storage/release capability. Materials, 12, 1286/1-1286/26 (2019). https://doi.org/10.3390/ma12081286

[24] Yoo S., Kandare E., Mahendrarajah G., Al-Maadeed M. A., Khatibi A. A.: Mechanical and thermal characterisation of multifunctional composites incorporating phase change materials. Journal of Composite Materials, 51, 2631-2642 (2017). https://doi.org/10.1177/0021998316673894

[25] Fredi G., Dorigato A., Pegoretti A.: Multifunctional glass fiber/polyamide composites with thermal energy storage/release capability. Express Polymer Letters, 12, 349-364 (2018).

https://doi.org/10.3144/expresspolymlett.2018.30

[26] Dorigato A., Fredi G., Pegoretti A.: Novel phase change materials using thermoplastic composites. AIP Conference Proceedings, 1981, 020044/1-020044/4 (2018). https://doi.org/10.1063/1.5045906 
[27] Fredi G., Dorigato A., Unterberger S., Artuso N., Pegoretti A.: Discontinuous carbon fiber/polyamide composites with microencapsulated paraffin for thermal energy storage. Journal of Applied Polymer Science, 136, 47408/1-47408/14 (2019).

https://doi.org/10.1002/app.47408

[28] Dorigato A., Fredi G., Pegoretti A.: Thermo-mechanical behavior of novel wood laminae-thermoplastic starch biodegradable composites with thermal energy storage/release capability. Frontiers in Materials, 6, 1-12 (2019).

https://doi.org/10.3389/fmats.2019.00076

[29] Fredi G., Dorigato A., Pegoretti A.: Novel reactive thermoplastic resin as a matrix for laminates containing phase change microcapsules. Polymer Composites, in press (2019).

https://doi.org/10.1002/pc.25233

[30] Fredi G., Dorigato A., Pegoretti A.: Effect of paraffin phase change on the dynamic-mechanical properties of the host laminate. Mechanics of Time-Dependent Materials, under revision (2019).

[31] Pielichowska K., Pielichowski K.: Phase change materials for thermal energy storage. Progress in Materials Science, 65, 67-123 (2014).

https://doi.org/10.1016/j.pmatsci.2014.03.005

[32] Fleischer A. S.: Thermal energy storage using phase change materials - Fundamentals and applications. Springer, Minneapolis (2015). https://doi.org/10.1007/978-3-319-20922-7

[33] Trigui A., Karkri M., Boudaya C., Candau Y., Ibos L., Fois M.: Experimental investigation of a composite phase change material: Thermal-energy storage and release. Journal of Composite Materials, 48, 49-62 (2014). https://doi.org/10.1177/0021998312468185

[34] Sharma R. K., Ganesan P., Tyagi V. V., Metselaar H. S. C., Sandaran S. C.: Developments in organic solid-liquid phase change materials and their applications in thermal energy storage. Energy Conversion and Management, 95, 193-228 (2015).

https://doi.org/10.1016/j.enconman.2015.01.084

[35] Khadiran T., Hussein M. Z., Zainal Z., Rusli R.: Encapsulation techniques for organic phase change materials as thermal energy storage medium: A review. Solar Energy Materials and Solar Cells, 143, 78-98 (2015). https://doi.org/10.1016/j.solmat.2015.06.039

[36] Jamekhorshid A., Sadrameli S. M., Farid M.: A review of microencapsulation methods of phase change materials (PCMs) as a thermal energy storage (TES) medium. Renewable and Sustainable Energy Reviews, 31, 531-542 (2014).

https://doi.org/10.1016/j.rser.2013.12.033
[37] Cao V. D., Pilehvar S., Salas-Bringas C., Szczotok A. M., Valentini L., Carmona M., Rodriguez J. F., Kjøniksen A-L.: Influence of microcapsule size and shell polarity on thermal and mechanical properties of thermoregulating geopolymer concrete for passive building applications. Energy Conversion and Management, 164, 198209 (2018).

https://doi.org/10.1016/j.enconman.2018.02.076

[38] Sari-Bey S., Fois M., Krupa I., Ibos L., Benyoucef B., Candau Y.: Thermal characterization of polymer matrix composites containing microencapsulated paraffin in solid or liquid state. Energy Conversion and Management, 78, 796-804 (2014).

https://doi.org/10.1016/j.enconman.2013.11.014

[39] Hassan A., Shakeel Laghari M., Rashid Y.: Micro-encapsulated phase change materials: A review of encapsulation, safety and thermal characteristics. Sustainability, 8, 1046/1-1046/32 (2016).

https://doi.org/10.3390/su8101046

[40] Cherif C., Tran N. H. A., Kirsten M., Brünig H., Vogel R.: Environmentally friendly and highly productive bicomponent melt spinning of thermoregulated smart polymer fibres with high latent heat capacity. Express Polymer Letters, 12, 203-214 (2018).

https://doi.org/10.3144/expresspolymlett.2018.19

[41] Sarier N., Onder E.: Organic phase change materials and their textile applications: An overview. Thermochimica Acta, 540, 7-60 (2012). https://doi.org/10.1016/j.tca.2012.04.013

[42] Iqbal K., Khan A., Sun D., Ashraf M., Rehman A., Safdar F., Basit A., Maqsood H. S.: Phase change materials, their synthesis and application in textiles - A review. The Journal of the Textile Institute, 110, 625-638 (2019). https://doi.org/10.1080/00405000.2018.1548088

[43] Salyer I. O.: Phase change materials incorporated throughout the structure of polymer fibers. U.S. Patent 5885475, USA (1999).

[44] Magill M. C., Hartmann M. H., Haggard J. S.: Multicomponent fibers having enhanced reversible thermal properties and methods of manufacturing thereof. U.S. Patent 6855422B2, USA (2005).

[45] Shin Y., Yoo D-I., Son K.: Development of thermoregulating textile materials with microencapsulated Phase Change Materials (PCM). II. Preparation and application of PCM microcapsules. Journal of Applied Polymer Science, 96, 2005-2010 (2005).

https://doi.org/10.1002/app.21438

[46] Hartmann M. H., Worley J. B., North M.: Temperature regulating cellulosic fibers and applications thereof. U.S. Patent 7579078B2, USA (2007).

[47] Leskovšek M., Jedrinović G., Elesini U. S.: Properties of polypropylene fibres with incorporated microcapsules. Acta Chimica Slovenica, 51, 699-715 (2004). 
[48] Gao X-Y., Han N., Zhang X-X., Yu W-Y.: Melt-processable acrylonitrile-methyl acrylate copolymers and meltspun fibers containing MicroPCMs. Journal of Materials Science, 44, 5877-5884 (2009).

https://doi.org/10.1007/s10853-009-3830-Z

[49] Salaün F., Creach G., Rault F., Almeras X.: Thermophysical properties of polypropylene fibers containing a microencapsulated flame retardant. Polymers for Advanced Technologies, 24, 236-248 (2013).

https://doi.org/10.1002/pat.3076

[50] Wang H. P., Yuan Y. C., Rong M. Z., Zhang M. Q.: Selfhealing of thermoplastics via living polymerization. Macromolecules, 43, 595-598 (2010).

https://doi.org/10.1021/ma902021v

[51] Wiegand N., Mäder E.: Commingled yarn spinning for thermoplastic/glass fiber composites. Fibers, 5, 26/126/15 (2017). https://doi.org/10.3390/fib5030026

[52] Zhang D.: Advances in filament yarn spinning of textiles and polymers. Woodhead, Cambridge (2014).

[53] Rothon R. N.: Effects of particulate fillers on flame retardant properties of composites. in 'Particulate filled polymer composites' (ed.: Rothon R. N.) Rapra, Shawbury, 263-302 (2003).

[54] Zhang X. X., Wang X. C., Tao X. M., Yick K. L.: Energy storage polymer/MicroPCMs blended chips and thermo-regulated fibers. Journal of Materials Science, 40, 3729-3734 (2005).

https://doi.org/10.1007/s10853-005-3314-8

[55] Brody H.: Process of melt spinning poly propylene and novel rough surfaced fibres produced thereby. U.S. Patent 4522884A, USA (1985).

[56] Rueda M. M., Fulchiron R., Martin G., Cassagnau P.: Rheology of polypropylene filled with short-glass fibers: From low to concentrated filled composites. European Polymer Journal, 93, 167-181 (2017).

https://doi.org/10.1016/j.eurpolymj.2017.05.025

[57] Doumbia A. S., Castro M., Jouannet D., Kervoëlen A., Falher T., Cauret L., Bourmaud A.: Flax/polypropylene composites for lightened structures: Multiscale analysis of process and fibre parameters. Materials and Design, 87, 331-341 (2015).

https://doi.org/10.1016/j.matdes.2015.07.139

[58] Rueda M. M., Auscher M-C., Fulchiron R., Périé T., Martin G., Sonntag P., Cassagnau P.: Rheology and applications of highly filled polymers: A review of current understanding. Progress in Polymer Science, 66, 22-53 (2017).

https://doi.org/10.1016/j.progpolymsci.2016.12.007

[59] Dorigato A., Pegoretti A., Penati A.: Linear low-density polyethylene/silica micro- and nanocomposites: Dynamic rheological measurements and modelling. Express Polymer Letters, 4, 115-129 (2010).

https://doi.org/10.3144/expresspolymlett.2010.16

[60] Poslinski A. J., Ryan M. E., Gupta R. K., Seshadri S. G., Frechette F. J.: Rheological behavior of filled polymeric systems I. Yield stress and shear-thinning effects. Journal of Rheology, 32, 703-735 (1988).

https://doi.org/10.1122/1.549987
[61] Osswald T. A., Rudolph N.: Polymer rheology: Fundamentals and applications. Hanser, Munich (2015).

[62] Carreau P. J.: Rheological equations from molecular network theories. Transactions of the Society of Rheology, 16, 99-127 (1972).

https://doi.org/10.1122/1.549276

[63] Wang S., Tozaki K-I., Hayashi H., Hosaka S., Inaba H.: Observation of multiple phase transitions in $\mathrm{n}-\mathrm{C}_{22} \mathrm{H}_{46}$ using a high resolution and super-sensitive DSC. Thermochimica Acta, 408, 31-38 (2003). https://doi.org/10.1016/s0040-6031(03)00312-5

[64] Rezaie A. B., Montazer M.: One-step fabrication of fatty acids/nano copper/polyester shape-stable composite phase change material for thermal energy management and storage. Applied Energy, 228, 1911-1920 (2018).

https://doi.org/10.1016/j.apenergy.2018.07.041

[65] Zhang P., Hu Y., Song L., Ni J., Xing W., Wang J.: Effect of expanded graphite on properties of high-density polyethylene/paraffin composite with intumescent flame retardant as a shape-stabilized phase change material. Solar Energy Materials and Solar Cells, 94, 360365 (2010).

https://doi.org/10.1016/j.solmat.2009.10.014

[66] Yuan W., Yang X., Zhang G., Li X.: A thermal conductive composite phase change material with enhanced volume resistivity by introducing silicon carbide for battery thermal management. Applied Thermal Engineering, 144, 551-557 (2018).

https://doi.org/10.1016/j.applthermaleng.2018.07.095

[67] Jeong S-G., Kim S., Huh W.: Preparation of epoxy resin using n-hexadecane based shape stabilized PCM for applying wood-based flooring. Journal of Adhesion Science and Technology, 28, 711-721 (2014).

https://doi.org/10.1080/01694243.2013.865331

[68] Huang X., Lin Y., Alva G., Fang G.: Thermal properties and thermal conductivity enhancement of composite phase change materials using myristyl alcohol/metal foam for solar thermal storage. Solar Energy Materials and Solar Cells, 170, 68-76 (2017).

https://doi.org/10.1016/j.solmat.2017.05.059

[69] Morton W. E., Hearle J. W. S.: Tensile properties. in 'Physical properties of textile fibres' (eds.: Hearle J. W. S., Morton W. E.) Woodhead, Cambridge, 274-321 (2008). https://doi.org/10.1533/9781845694425.274

[70] Iqbal K., Sun D.: Development of thermal stable multifilament yarn containing micro-encapsulated phase change materials. Fibers and Polymers, 16, 1156-1162 (2015). https://doi.org/10.1007/s12221-015-1156-9

[71] Cho J-S., Kwon A., Cho C-G.: Microencapsulation of octadecane as a phase-change material by interfacial polymerization in an emulsion system. Colloid and Polymer Science, 280, 260-266 (2002). https://doi.org/10.1007/s00396-001-0603-x 